CAHIER 9560

\title{
A MODEL OF COMPARATIVE STATICS FOR CHANGES IN STOCHASTIC RETURNS WITH DEPENDENT RISKY ASSETS
}

\author{
Georges Dionne' \\ Christian Gollier
}

1 Département de sciences économiques and Centre de recherche sur les transports (C.R.T.), Université de Montréal

2 Institut d'économie industrielle, Université des Sciences Sociales de Toulouse

\section{December 1995}

This paper extends Dionne and Gollier (1992). We thank F. Gagnon, L. Eeckhaudt anc $T$. Mounsif for their comments on earlier versions. The financial supports of the Consei de recherches en sciences humaines du Canada (C.R.S.H.) and the Fédération française des sociétés d'assurance (F.F.S.A. - France) are acknowledged. J. Leblanc, J. Plante and $C$. Michaud were very useful in the preparation of the manuscript. 
Ce cahier a également été publié au Centre de recherche sur les transports (C.R.T.) (publication no 95-83)

Dépót légal - 1995

Bibliotheque nationale du Québec

Bibliothèque nationale du Canada 


\section{ABSTRACT}

In this paper we show how the order of Greater Central Riskiness proposed by Gollier (199 can be applied to situations with dependent risky assets. This order was shown to be the le: constrained necessary and sufficient condition 10 guarantee that all risk-averse agents reduce the demand for a risky position when a marginal increase in risk is imposed in a model with or risky asset. Recently Hadar and Seo (1990) and Meyer and Ormiston (1994) have proposed in models of comparative static changes with more than one risky asset. They obtained that standar conditions on preferences for comparative statics with one random parameter remain valid. Het we introduce a different extension by considering restrictions on changes in risk instead c restrictions on utility functions. We show how the concept of Linear Stochastic Dominanc generates the desired results for mean preserving spreads and first order stochastic dominance: Strong increases in risk (Meyer and Ormiston, 1985) are examples of mean preserving spreald that satisfy the condition. Other examples are discussed.

Key words : Changes in risk, linear stochastic dominance, risky assets, simple increases in risk

\section{RÉSUMÉ}

Dans cet article nous montrons comment le concept d'accroissement de risque central proposé par Gollier (1995) peut étre appliqué à des situations avec plusieurs actifs risqués dépendants. Ce concept est connu comme étant la condition nécessaire et suffisante la moins restrictive qui garantit que tous les individus riscophobes vont réduire leur demande pour une position risquée lorsque des accroissements de risque marginaux sont imposés dans un modèle avec une seule variable aléatoire. Récemment, Hadar et Seo (1990) et Meyer et Ormiston (1994) ont proposé deux modèles de statique comparative pour des situations avec plus d'une variable aléatoire. Ils ont vérifié que les conditions classiques sur les préférences des modèles avec une variable aléatoire demeurent valides. Ici nous introduisons une extension différente en considérant des restrictions sur les changements de risque plutôt que sur les fonctions d'utilité. Nous montrons que le concept de dominance stochastique linéaire génère les résultats désirés pour des accroissements de risque à moyenne constante et pour des dominances stochastiques de premier ordre. Les accroissements de risque forts (Meyer et Ormiston, 1985) sont des exemples qui satisfont la condition. D'autres exemples sont discutés.

Mots-clefs : changements de risque, dominance stochastique linéaire, actifs risqués, accroissements de risque simples. 



\section{INTRODUCTION}

In a recent article Gollier (1995) proposed the least constrained necessary and sufficient conditior on a change in distribution for signing the effect of a marginal change in risk on the optima decision variable for all risk averse agents. The model was applied to the class of linear payoffs where the order of "Greater Central Riskiness" was shown to be necessary and sufficient to guarantee that all risk - averse agents reduce their optimal demand for a risky position. The standard porttolio problem is a good example of such application; the coinsurance problem and the competitive firm with constant marginal cost are other examples of linear payoff'.

The object of this paper is to extend the above results to problems with two stochastically dependent risky assets. Although these more general problems correspond to many economic applications such as the composition of optimal portfolios in finance or the determination of optimal capital structures (see Dewatripont and Tirole (1994) and Boyd and Smith (1994)), only few authors have analyzed the effect of changes in risk on the optimal decision variables. Hadar and Seo (1990) did a first contribution to the literature by considering general changes in asset returns with risky returns that are independently distributed both before and after one return is altered. They showed that the conditions on preferences proposed by Rothschild and Stiglitz (1971) remain necessary and sufficient with independence. One condition, to obtain the desired result following a mean preserving spread, states that $Z^{\prime}(Z)$ be concave in $Z$ where $Z$ is final wealth and $U(Z)$ is a concave utility function. For a first order stochastic dominance $Z U^{\prime}(Z)$ has to be non decreasing. More recently, Meyer and Ormiston (1994) extended their results to dependent risky returns and showed that the same conditions on utility remain necessary and sufficient when the independence assumption is replaced by stochastic dependence.

In this paper we propose a different extension of Hadar and Seo (1990) contribution by considering restrictions on the set of changes in risk for all risk averse individuals instead of restrictions on utility functions. We show how the order of Greater Central Riskiness can be extended to models with two dependent risky assets. This extension can be applied to mean preserving spreads (MPS) and first-order stochastic dominances (FSD). Its relationship with second order stochastic dominances (SSD) is also discussed.

See Dionne, Eeckhoud and Gollier (1993) for an anatysis of increases In risk and linear payofis. 


\section{MODEL}

Consider a risk averse investor with a twice continuously differentiable, strictly increasing and concave von Neuman - Morgenstern utility function of wealth ${ }^{2}(W) ; u^{\prime}(W)>0, u^{\prime \prime}(W)<0$. He must allocate his unit of capital in two risky assets with returns $\bar{x}$ and $\tilde{y}$. His terminal wealth is then equal to $\tilde{z}=b \tilde{x}+(1-b) \tilde{y}$ with $b$ being the proportion of funds invested in asset $X$.

Stochastic dependence is allowed. Therefore, the initial risky situation is described by a joint cumulative distribution of returns $H_{1}(x, y)$ and its corresponding joint density $h_{1}(x, y)$. Returns $\tilde{x}$ and $\tilde{y}$ take their values in the respective intervals $[\underline{x}, \bar{x}]$ and $[y, \bar{y}]$ and rectangle $[x, \bar{x}] X[y, \bar{y}]$ contains the support of $H_{1}(x, y)$. The problem of the investor is to select a portfolio that maximizes his expected utility :

$$
b\left(u, H_{1}\right) \in \operatorname{argmax} U\left(b ; u, H_{1}\right)=\int_{x}^{x} \int_{I}^{\nabla} u(b x+(1-b) y) d H_{1}(x, y) .
$$

Let hereafter $b$, denote $b\left(u, H_{1}\right)$.

The objective of the paper is to determine the effect of an increase in portfolio returns distribution of asset $x$ on the optimal portfolio choice. Suppose that $H_{1}(x, y)$ is replaced by a new distribution $H_{2}(x, y)$ and denote $b_{2}$ as the optimal solution with distribution $H_{2}(x, y)$ having its support in the rectangle $[x, \bar{x}] X[y, \bar{y}]$, l.e. $b_{2}=b\left(u, H_{2}\right)$. The question is then to find the least restrictive sufficient condition which guarantees that all risk averse investors (with no other restriction than risk aversion) will react to the new risky situation by reducing the demand for the asset $x$, i.e. $b_{2} \leq b_{1}$. Both FSD and MPS will be analyzed formally.

If $b_{1}$ is inite ${ }^{3}$, it must satisfy the following first - order condition :

$$
\frac{\partial U}{\partial b}\left(b_{1}\right)=\int_{\underline{x}}^{x} \int_{Y}^{\nabla} u^{\prime}\left(b_{1} x+\left(1-b_{1}\right) y\right)(x-y) d H_{1}(x, y)=0 .
$$

2 Since no restriction will be imposed on the utility function, risk aversion is sufficient to get all the results. However, Hadar and Seo (1990) and Meyer and Ormiston (1994) had to impose that $U^{* \prime \prime}(W) \geq 0$ to obtain their resuns tor a MPS. 
By risk aversion the second order condition is satisfied. Then a necessary and sufficient conditic for $b_{2}<b_{1}$, is that the derivative of the objective function with the new distribution $H_{2}\left(x_{1}\right.$ : evaluated at $b=b_{1}$ be negative. In other words, $b_{2}<b_{1}$, if and only if :

$$
\frac{\partial U}{\partial b}\left(b_{1}\right)=\int_{\underline{x}}^{\Sigma} \int_{y}^{y} u^{\prime}\left(b_{1} x+\left(1-b_{1}\right) y\right)(x-y) d H_{2}(x, y)<0 .
$$

Before presenting detailed analysis with two random parameters, we first recall some results fror models in the literature with only one risky asset in order to make connection with our results.

\section{Changes in Risk with a Safe Asset and one Risky parameter}

To obtain direct comparisons, we assume, for the moment, that $\tilde{y}$ takes value $r$ with probabilit one, both before and after any change in risk. In the interpretation of the portfolio problem, $r$ is the risk-free interest rate. Equilibrium on capital markets implies that $E_{i}(x) \geq r$ so that $b_{1}$ is positive for $\mathrm{i}=1,2$.

Let $F_{1}(x)$ denote the cumulative function of $x$. We first restate the definition of location - weightec probability mass proposed by Landsberger and Meilijson (1990). The location - weightec probability mass of the tail $[\underline{x}, x]$ with respect to the distribution $F_{1}$ around $r$ is given by :

$$
T_{1}(x, r)=\int_{\underline{x}}^{x}(t-r) d F_{1}(t) .
$$

$T_{1}(x, r)$ has two properties that will be useful :

$$
\begin{aligned}
T(x, r) & =0 \\
\text { and } \frac{\partial T_{1}}{\partial x}(x, r) & =(x-r) F_{1}^{\prime}(x)
\end{aligned}
$$

This derivative is continuous in $x$ and its sign is given by $(x-r)$; it is then independent of the distribution function. 
This concept $\left(T_{1}(x, r)\right)$ is useful for the following definition :

Definition 1: Consider two random parameters $\tilde{x}_{1}$ and $\tilde{x}_{2}$ with respective distribution functions $F_{1}(x)$ and $F_{2}(x)$. $\tilde{x}_{1}$ dominates $\tilde{x}_{2}$ in the sense of Linear Stochastic Dominance of factor $y$ for $a$ given r, i.e. $\tilde{x}_{1} L S D_{\gamma, r} \tilde{x}_{2}$, if $\exists \gamma$ such that $T_{2}(x ; r) \leq \gamma T_{1}(x, r) \forall x \in[x, \bar{x}]$. Moreover $\tilde{x}_{1}$ Centrally Dominates $\tilde{x}_{2}$ around $r$, i.e. $\tilde{x}_{1} C D, \tilde{x}_{2}$, if there exists $\gamma \in R$ such that $\tilde{x}_{1} L S D_{\gamma, t} \tilde{x}_{2}$

We know the following result :

Proposition 1: (Gollier (1995)) : Consider the standard portfolio problem with risk-free rate $r<E\left(\tilde{x}_{1}\right)$. All risk-averse investors reduce their demand for the risky asset when its returns undergo a change in distribution from $\tilde{x}_{1}$ to $\tilde{x}_{2}$ if and only if $\tilde{x}_{1} C D_{8} \tilde{x}_{2}$.

The examples of $C D_{1}$ that restrict $\tilde{x}_{1}$ and $\tilde{x}_{2}$ to have the same mean are Strong Increases in Risk (SIR, Meyer and Ormiston (1985)), Relatively Strong Increases in Risk (RSIR, Black and Bulkley (1984)) and Relatively Weak Increases in Risk (RWIR, Dionne, Eeckhoudt and Gollier (1993)).

The two last examples imply that $\exists \gamma$ such that $\tilde{x}_{1} L_{S D_{y}} \tilde{x}_{2} . \gamma$ is not necessarily equal to one while it has to be equal to one in SIR. Another definition implying $\gamma=1$ is a Simple Increase in Fisk around $r$ (sIR, Dionne and Gollier (1992)). Hammond (1974) considered a similar kind of restrictions on increases in risk. He used a single-crossing condition on cumulatives distributions to asses risk aversion. Finally, note that a Second-Degree Stochastic Dominance (SSD) is neither necessary nor sufficient for CD, (Corollary 2 in Gollier (1995)).

We may also consider another example of $C D_{r}$ that does not restrict the two distributions to the same mean : $\tilde{x}_{1}$ dominates $\tilde{x}_{2}$ in the sense of Strong Linear Stochastic Dominance of factor $\gamma$ aroud r, l.e. $\tilde{x}_{1} S L S D_{n,}, \tilde{x}_{2}$, if and only if

$$
\begin{array}{ll}
F_{2}^{\prime}(x) \geq \gamma F^{\prime}{ }_{1}(x) & \text { when } x \leq r \\
F_{2}^{\prime}(x) \leq \gamma F_{1}^{\prime}(x) & \text { when } x \geq r
\end{array}
$$

or, if and only if

$$
\min _{x \leq r} \frac{F_{2}^{\prime}(x)}{F_{1}^{\prime}(x)} \geq \max _{x \geq r} \frac{F_{2}^{\prime}(x)}{F_{1}^{\prime}(x)} .
$$


To obtain a SLSD, enough probability mass must be transferred from returns greater than $r$ returns less than $\mathrm{r}$. Figure 1 is an example of SLSD :

(Figure 1 about here)

Note that a SLSD with a constant parameter can represent a First-Order Stochastic Dominanc (FSD). This particularity will be important to derive the comparative statics results. The ne) proposition establishes the links between SLSD and LSD.

Proposition 2: If $\exists \gamma$ such that $\tilde{x}_{1} \operatorname{SLSD}_{\gamma,} \tilde{x}_{2}$, then $\tilde{x}_{1} \operatorname{LSD}_{\gamma_{1}} \tilde{x}_{2}$.

Proof : Immediate by observing that $T_{2}(x, r)-\gamma T_{1}(x, r)=\int_{\Sigma}^{x}(t-r)\left(d F_{2}(t)-\gamma d F_{1}(t)\right)<0$ since $(t-r)\left(d F_{2}(t)-\gamma d F_{1}(t)\right) \leq 0, \forall t$, by definition of SLSD.

Since SIR and sIR will be used in the next section, we remind their definitions :

SIR (Meyer and Ormiston, 1987) : let the interval $\left[x_{3}, x_{4}\right]$ be the support of $x$ with distribution $F$,

We say that $F_{2}$ is a strong increase in risk of $F_{1}$ if and only if

a) the mean is preserved;

b) $F_{2}(x)$ is always less or equal to $F_{1}(x)$ inside the support of $F_{1}$.

sIR (Dionne and Gollier, 1992) : $F_{2}$ is a simple increase in risk across $r$ of $F_{1}$ if and only if

a) the mean is preserved;

b) $\quad F_{2}(x)$ is larger than $F_{1}(x)$ whenever $x$ is less than $r$ and $F_{2}(x)$ is less than $F_{1}(x)$ whenever $x$ is larger than $r$ :

$$
\left(F_{2}(x)-F_{1}(x)\right)(x-r) \leq 0 \forall x \in[\underline{x}, \bar{x}]
$$

We now show how these concepts are useful for the comparative statics analysis of changes in risk with dependent risky assets. 


\section{INCREASES IN RISK WTH STOCHASTICALIY DEPENDENT ASSETS}

We demonstrate in this section how the $\mathrm{LSO}_{\gamma, \text { }}$ definition of change in riskiness can be applied to the case of multiple risky assets. We allow for any kind of stochastic dependence between $\tilde{x}$ and $\tilde{y}$. As discussed in detail by Meyer and Ormiston (1994), the main problem that one faces when considering two stochastically dependent variables is to fix the ceteris paribus assumption. Here we use the same assumption that we proposed in our first contribution to the subject (Dionne and Gollier (1992)) and applied by Dewatripont and Tirole (1994) to the choice of optimal capital structure. The central idea is the following : let us define the joint distribution of $\tilde{x}$ and $\tilde{y}$ as $H_{1}(x, y)=F_{1}(x \mid y) g_{i}(y)$ where $F_{1}(x \mid y), i=1,2$, is the distribution of asset $x$ conditional on $y$ and $g_{i}(y)$ is the marginal density of $y$. Because we analyze the effect of a change in risk for asset $x$, we assume that the marginal distribution for asset $y$ remains unchanged, that is $g_{1}(y)=g_{2}(y)$. This is the ceteris paribus assumption that we use. Recently, Gagnon (1994) has shown that this assumption implies that the sign of the correlation between $\tilde{x}$ and $\tilde{y}$ remains constant for any mean preserving spread of $\tilde{x}$ that assumes a fix marginal distribution of $\tilde{y}$. See Meyer and Ormiston (1994) for a more detailed discussion of a similar ceteris paribus condition and for an example. We are now ready to prove the following result.

Proposition 3: Assume $b_{4}$ be non-negative. Then a sufficient condition for $b_{2} \leq b_{1}$ for all riskaverse investors is that there exists a scalar $\gamma$ such that $\left.\tilde{x}_{1}\right|_{y} L S D_{y, y} \tilde{x}_{2} l_{y}$ for all $y$, i.e. $\exists y \forall x \in[\underline{x}, \bar{x}]$, $\forall y \in[x, \bar{y}]: T_{2}(x, y) \leq \gamma T_{1}(x, y)$.

Proof : From (3), by using the definition of $H_{2}(x, y)=F_{2}(x \mid y) g(y)$, we obtain :

$$
\left.\frac{\partial U}{\partial b}\left(b_{1}\right)=\int_{y}^{x} \int_{x}^{x} u^{\prime}\left(b_{1} x+\left(1-b_{1}\right) y\right)(x-y) d F_{2}(x \mid y)\right\} g(y) d y .
$$

Integrating by parts yields

$$
\begin{aligned}
\frac{\partial U}{\partial b}\left(b_{1}\right) & ={ }_{y}^{J}\left\{u^{\prime}\left(b_{1}(\bar{x}-y)+y\right) T_{2}(\bar{x}, y)\right. \\
& -b_{1} \int_{\underline{x}}^{x}\left(u^{\prime \prime}\left(b_{1}(\bar{x}-y)+y\right) T_{2}(x, y) d x\right\} g(y) d y .
\end{aligned}
$$


By assumption, we have $T_{2}(x, y) \leq \gamma T_{1}(x, y)$ for all $x, y$. This condition logether with the assumpt that $b$, is non-negative yields :

$$
\begin{aligned}
\frac{\partial U}{\partial b}\left(b_{1}\right) & \leq \int_{y}^{7}\left\{u^{\prime}\left(b_{1} \sqrt{x}-y\right)+y\right) \gamma T_{1}(\bar{x} ; y) \\
& \left.-b_{1} \int_{\frac{x}{y}}^{x} u^{\prime \prime}\left(b_{1}(x-y)+y\right) \gamma T_{1}(x ; y) d x\right) d G(y) \\
& =\gamma \int_{y}^{\frac{x}{x}}\left\{u^{\prime}\left(b_{1}(\bar{x}-y)+y\right) T_{1}(\bar{x} ; y)\right. \\
& \left.-b_{1} \int_{\frac{x}{u}}^{u^{\prime \prime}}\left(b_{1}(x-y)+y\right) T_{1}(x, y) d x\right\} d G(y) \\
& =\gamma \frac{\partial U}{\partial b}\left(b_{1} ; u, H_{1}\right)=0 .
\end{aligned}
$$

Thus $b_{2} \leq b_{1}$. This completes the proof.

Notice that Proposition 3 provides the weakest condition on the changes in the condition: distribution of $\tilde{x}$ that yields the comparative statics property without putting any constraint on th concave utility function, or on the marginal distribution of $\tilde{y}$. Indeed, suppose that for at least on $y$, there is no $\gamma$ such that $\tilde{x}_{1}\left|y \quad L S D_{y, y} \tilde{x}_{2}\right| y$. Then if we assume that the marginal distribution o $\bar{y}$ be degenerated at $y_{3}$ it is a direct consequence of Proposition I that there exists a concave utility function $u$ such that $b\left(u, H_{2}\right)$ is larger that $b\left(u, H_{1}\right)$.

Proposition 3 provides the instrument to extend all analyses performed for the one-safe-one-risky. asset model. For example, remember that Strong increases in risk belongs to the larger set of changes in risk that satisfy $L_{S D_{1, y}}$ for any $y$. Thus, if the changes in the conditional distribution of $\tilde{x}$ all satisfy the SIR condition for all $y$, Proposition 3 guarantees that the demand for $x$ will be reduced due to these changes. Similarly, if $\tilde{x}_{1} \mid y$ dominates $\tilde{x}_{2} \mid y$ in the sense of a Simple increase in risk around $y$, for any $y$, then the same result holds. Proposition 3 shows how to go beyond these simple results. Indeed, since simple increases in risk around $y$ also belong to the set of $L_{S D_{1, y}}$, an unambigous comparative statics property is also obtained for "combined incrases in risk" performed on the conditional distributions of $\tilde{x}$. We say that $\tilde{x}$ undergoes a combined increase in risk if for any $y, \tilde{x}_{1} \mid y$ dominates $\tilde{x}_{2} \mid y$ either in the sense of a simple incrase in the risk around $y$, or in the sense of a strong increase in risk. What is new here is the possibility to mix SIR for some $y$ and SIR for others. 
One can also use Proposition 3 for changes in risk that belong to $L S D_{x, y}$, for $\gamma$ different from unity. For example, it there exists a scalar $\gamma$ such that all conditional distributions undergo a SLSD of factor $\gamma$ around the corresponding $y$, then the comparative statics result holds. Still, we urge the reader to observe that a false extension to the result by Gollier (1995) would be to claim the following result : if for every $y$, there exists a scalar $x(y)$ such that $\tilde{x}_{1}\left|y L_{y-1} D_{y y} \tilde{x}_{2}\right| y$, then $b_{2} \leq b_{1}$. Or equivalently, it for every $y, \tilde{x}_{1}\left|y \quad C R_{y} \tilde{x}_{2}\right| y$, then $b_{2} \leq b_{1}$. In short, the quantifiers " $\exists \gamma$ and " $\forall y$ " may not be inverted in Proposition 3. Consequently, we may not infer for this Proposition 3 that if all conditional distributions undergo a relatively strong increase in risk, then $\mathrm{b}_{2} \leq \mathrm{b}_{1}$. A counter-example is given in the next section. This is due to the fact that different RSIR may belong to $\mathrm{LSD}_{\gamma, y}$ sets of different $\gamma$.

Another application is a SLSD on $x$. When a SLSD is a first order stochastic dominance, since this is a particular case of a $L S D_{\gamma, y}$ it is immediate to verify that all risk averters will reduce their position on asset $x$.

\section{A COUNTER-EXAMPLE IN THE CASE OF RSIR}

Proposition 3 shows clearly that we cannot apply directly the order of Greater Central Riskiness developed for one risky asset to problems with two stochastically dependent risks. In fact, as discussed above, a false extension to the results in Gollier (1995) would be to claim the following result when $b_{1}>0:$ If $\tilde{x}_{1}\left|y C D_{1} \tilde{x}_{2}\right| y$ for all $y$, then $b_{2} \leq b_{1}$. The following counter example shows that it is necessary to assume that $\tilde{x}_{1}\left|y \quad L_{S D_{y, y}} \tilde{x}_{2}\right| y$ with the same $y$ for all $y$ to obtain the desired result.

Counter example: By construction of the example, let

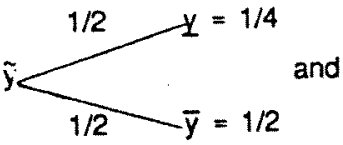

$\tilde{x}_{1} \sqrt{y} \equiv \tilde{x}_{2} \mid \bar{y} \equiv 13 / 32$ with probability 1 . Obviously $\tilde{x}_{1} \sqrt{y} \quad \operatorname{LSD}_{1, y} \quad \tilde{x}_{2} \sqrt{y}$. 
Now suppose that $\tilde{x}_{1} l y$ is uniformly distributed on $[0,1]$ and define the following compoun lottery:

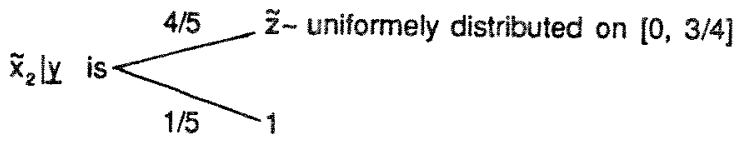

We observe that $\tilde{x}_{2} \mid \mathcal{L}$ is a Relatively Strong increase in Pisk (Black and Bulkley (1989)) of $\tilde{x}_{1} \mid y$ More precisely, $\tilde{x}_{1} \mid y$ LSD $_{1615, y} \tilde{x}_{2} l y$. However, $\tilde{x}_{1} \mid y$ does not LSD, $\tilde{x}_{2} \mid y$.

We observe that $\tilde{x}_{1}$ is less risky than $\tilde{x}_{2}$ but with a more general definition than in Proposition: in the sense that wo different values of $y$ have been used. We now show that $b_{2}>b_{1}$ for $a$ nol decreasing and concave utilty function. Let $u(z)=\min (z, 1 / 2)$. We first show that $b_{1}=1 / 2$.

$$
\begin{aligned}
\frac{\partial U}{\partial b}(1 / 2) & \left.=1 / 2 E\left[\left.\tilde{x}_{1}\right|_{y}-y\right] u^{\prime}\left(\frac{\left.\tilde{x}_{1}\right|_{y}+y}{2}\right)\right] \\
& +1 / 2 E\left[\left[\left.\tilde{x}_{1}\right|_{y}-\bar{y}\right] u^{\prime}\left(\frac{\left.\tilde{x}_{1}\right|_{y}+\bar{y}}{2}\right)\right\} \\
& =1 / 2 \times \frac{x+1 / 4}{2}=1 / 2 \\
& =1 / 2\left[\frac{x^{2}}{2}-\frac{x}{4}\right]_{0}^{3 / 4}+1 / 2(-3 / 32)=3 / 32(1 / 2-1 / 2)=0
\end{aligned}
$$

We now verify that $b_{2}>1 / 2$

$$
\begin{aligned}
\frac{\partial U}{\partial b}\left(\frac{1}{2}\right) & =\frac{1}{2} \int_{0}^{\frac{3}{4}} \frac{16}{15}\left(x-\frac{1}{4}\right) d x+\frac{1}{2}\left(-\frac{3}{32}\right) \\
& =\frac{1}{2}\left(\frac{16}{15} \cdot \frac{3}{32}\right)+\frac{1}{2}\left(-\frac{3}{32}\right)=\frac{1}{320}>0
\end{aligned}
$$

In fact one obtains that $b_{2}=\sqrt{\frac{16}{61}}=0.5121>1 / 2$. 


\section{CONCLUSION}

We have extended the order of Greater Central Riskiness to environments with two risky dependent random variables. We have shown that, even when we use a definition of changes in risk that maintains the correlation sign between the two risky assets (ceteris paribus assumption), we must restrict the definition of greater riskiness to obtain intuitive comparative statics results for all risk averse individuals. We obtain that maintaining the same linear stochastic dominance structure between the two random variables $\left(\mathrm{LSD}_{\gamma, y}\right)$ is sufficient to get the desired result for a mean preserving spread.

We must emphasize however that our model generalizes other restrictions on changes in risk with two dependent risky parameters (such as Strong Increase in Risk and Simple Increase in Risk) and allow for any kind of stochastic dependence between the risky parameters. Moreover no other restriction than risk aversion is necessary. This means that our results can be used to study increases in risk in standard portfolio models. Simple increases in risk, tor example, can be applied to many distributions of assets returns. Finally, we have shown that a strong linear stochastic dominance (SLSD) can be interpreted as a first order stochastic dominance. However, it cannot be directly associated to a second order stochastic dominance (see Gollier (1995) for more details). 


\section{References}

BLACK, J.M. and G. BULKLEY (1989), A Ratio Criterion for Signing the Effect of an Increase ir Uncertainty, International Economic Review, 30, 119-130.

BOYD, J.H. and B.D. SMITH, (1994), The Use of Debt and Equity in Optimal Financial Contracts Working paper 537. Federal Reserve Bank of Minneapolis.

DEWATRIPONT, M. and J. TIROLE (1994), A Theory of Debt and Equity : Diversity of Securities and Management-Shareholder Concurrence, Quarterly Journal of Economic, 109, 1027-54.

DIONNE, G., L. EECKHOUDT and C. GOLLIER, (1993), Increases in Risk and Linear Payofts, International Economic Review, 34, 309-319.

DIONNE, G and C. GOLLIER, (1992), Comparative Statics Under Multiple Sources of Risk with Applications to Insurance Demand, The Geneva Papers on Risk and Insurance Theory, 17, 21-33.

DIONNE, G. and C. GOLLIER, (1992), Simple Increases in Risk and their Comparative Statics for Portfolio Management, Working Paper 9203, Economics Department, University of Montreal.

GAGNON, F., (1994), Increases in Risk With Two Dependent Stochastic Parameters : Some New Considerations, Miméo, Université de Montréal.

GOLLIER, C., (1995), The Comparative Statics of Changes in Risk Revisited, Journal of Economic Theory, 66, 522-535.

HADAR, J. and T.K. SEO, (1990), The Effects of Shifts in a Return Distribution on Optimal Portfolios, International Economic Review, 31, 721-736.

HAMMOND, J.S., (1974), Simplifying Choices Between Uncertain Prospects When Preference is Nonlinear, Management Science 20, 1047-1072.

LANDSBERGER, M. and I. MEILIJSON, (1990), A Tale of Two Tails : An Alternative Characterization of Comparative Risk, Joumal of Risk and Uncertainty, 3, pp. 65-82.

MEYER, J. and M.B. ORMISTON, (1994), The Effect on Optimal Portfolios of Changing the Return to a Risky Asset : the Case of Dependent Risky Returns, International Economic Review, 35, 603-612.

MEYER, J. and M.B. ORMISTON, (1985), Strong Increases in Risk and their Comparative Statics, International Economic Review, 26, 425-437.

ROTHSCHILD, M. and J. STIGLITZ, (1970), Increasing Risk : I. A Definition, Journal of Economic Theory, 2, 225-243.

ROTHSCHILD, M. and J. STIGLITZ, (1971), Increasing Risk : II. Its Economic Consequences, Journal of Economic Theory, 3, 66-84. 


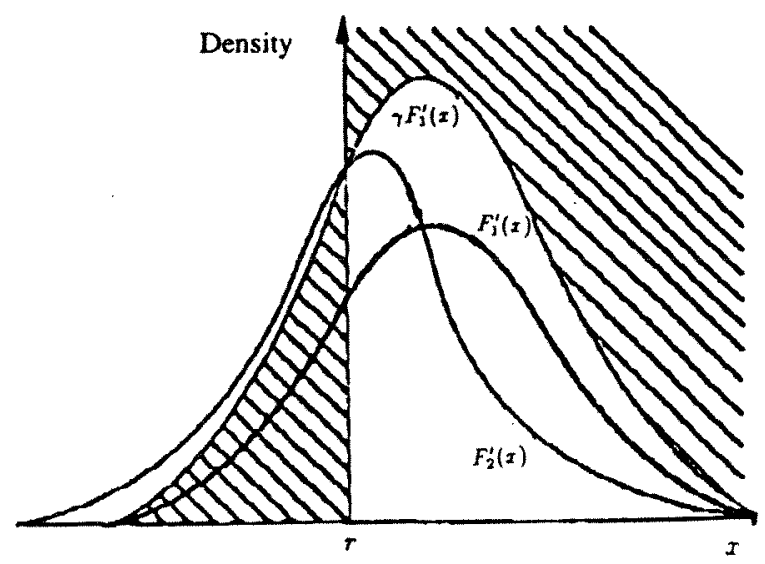

Figure 1. $F_{1}$ dominates $F_{2}$ in the sence of SLSD. 


\section{Université de Montréal \\ Departement de sciences économiques \\ Centre de documentation \\ C.P. 6128, succursale Centre-ville \\ Montréal (Québec) \\ H3C 3J7}

Cahiers de recherche (Discussion papers)

1994 à aujourd'hui (1994 to date)

Si vous désirez obtenir un exemplaire, vous n'avez qu'd faire parvenir votre demande el votre paiement (5\$ l'unite) d l'adresse ci-haut mentionnée. I To obtain a copy (\$5 each), please send your request and prepayment to the above-mentioned address.

9401 : Mercenier, Jean et Bemardin Akitoby, "On Intenemporal General-Equilibrium Reallocation Effects of Europe's Move to a Single Market", janvier 1994, 41 pages.

9402: Gauthier, Céline et Michel Poitevin, "Using Ex Ante Payments in Self-Enforcing Risk-Sharing Contracts", fevrier 1994, 38 pages.

9403 : Ghysels, Eric et Joanna Jasiak, "Stochastic Volatility and Time Deformation : an Application of Trading Volume and Leverage Effects", février 1994, 37 pages.

9404 : Dagenais, Marcel G. et Denyse L. Dagenais, "GMM Estimators for Linear Regression Models with Errors in the Variables", avril 1994. 33 pages.

9405: Bronsard, C.. Fabienne Rosenwald et Lise Salvas-Bronsard, "Evidence on Corporate Private Debt Finance and the Term Structure of Interest Rates", avril 1994, 42 pages.

9406: Dinardo, John, Nicole M. Forin et Thomas Lemieux, "Labor Market Institutions and the Distribution of Wages, 1973-1992 : A Semiparametric Approach", avril 1994, 73 pages.

9407 : Campbell, Bryan et Jean-Marie Dufour, "Exact Nonparametric Tests of Orthogonality and Random Walk in the Presence of a Drift Parameter", avril 1994, 32 pages.

9408: Bollerslev, Tim et Eric Ghysels, "Periodic Autoregressive Conditional Heteroskedasticity", mai 1994, 29 pages.

9409: Cardia, Emanuela, "The Effects of Govemment Financial Policies : Can We Assume Ricardian Equivalence?", mai 1994, 42 pages.

9410 : Kollmann, Rober, "Hidden Unemployment : A Search Theoretic Interpretation", mai 1994, 9 pages.

9411 : Kollmann, Rober. "The Correlation of Productivity Growth Across Regions and Industries in the US", juin 1994, 14 pages.

9412 : Gaudry, Marc, Benedikt Mandel et Werner Rothengatter, "Introducing Spatial Competition through an Autoregressive Contiguous Distributed (AR-C-D) Process in Intercity Generation-Distribution Models within a Quasi-Direct Format (QDF)", juin 1994, 64 pages.

9413 : Gaudry, Marc et Alexandre Le Leyzour, "Improving a Fragile Linear Logit Model Specified for High

9414 : Lewis, Tracy et Michel Poitevin. "Disclosure of Information in Regulatory Proceedings", juillet 1994, 38 pages.

9415 : Ambler, Steve, Emanuela Cardia et Jeannine Farazli, "Expon Promotion and Growth", août 1994, 41 pages.

9416: Ghysels, Eric et Haldun Sarian, "On the Analysis of Business Cycles Through the Spcctrum of Chronologies", ao0t 1994, 37 pages.

9417 : Martel, Jocelyn et Timothy C.G. Fisher, "The Creditors' Financial Reorganization Decision : New Evidence from Canadian Data", aout 1994, 21 pages.

9418 : Cannings, Kathy, Claude Montmarquette et Sophie Mahseredjian, "Entrance Quotas and Admission to Medical Schools : A Sequential Probit Model", septembre 1994, 26 pages. 
9419 : Cannings, Kathy, Claude Montmanquette et Sophie Mahseredjian. "Major Choices : Undergraduate Concentrations and the Probability of Graduation", septembre 1994, 26 pages.

9420 : Nabeya, Seiji et Pierre Perron. "Approximations to Sorne Exac Distributions in the First Order Autoregressive Model with Dependent Errors", septembre 1994, 40 pages.

Perron, Pierre, "Further Evidence on Breaking Trend Functions in Macroeconomic Variables", octobre 1994, 50 pages.

9422 : Vogelsang. Timothy J. et Pierre Perron, "Additional Tests for a Unit Root Allowing for a Break in the Trend Function at an Unknown Time", novembre 1994, 57 pages.

9423: Ng, Serena et Pierre Perron, "Unit Root Tests in ARMA Models with Data Dependent Methods for the Selection of the Truncation Lag", decembre 1994, 41 pages.

9424 : Perron. Pierre, "The Adequacy of Asymptotic Approximations in the Near-Integrated Autoregressive Model with Dependent Errors", decembre 1994, 37 pages.

Ghysels, Eric et Pierre Perron. "The Effect of Linear Filters on Dynamic Time Series with Structural Change", decembre 1994, 35 pages.

9426 : Boyer, Marcel, Jean-Jacques Laffont, Philippe Mahenc et Michel Moreaux, "Sequential Location Equilibria Under Incomplete Information", decembre 1994, 38 pages.

9427 : Perron. Pierre et Serena NG, "Useful Modifications to Some Unit Root Tests with Dependent Errors and their Local Asymptotic Properties", décembre 1994, 41 pages.

9428 : Garcia, René et Pierre Perron, "An Analysis of the Real Interest Rate Under Regime Shifts", decembre 1994. 42 pages.

Boyer, Marcel et Jean-Jacques Laffont, "Environmental Risks and Bank Liability", janvier 1995, 46 pages.

Margolis, David. N., "Firm Heterogeneity and Worker Self-Selection Bias Estimated Retums to Seniority", décembre 1994, 29 pages.

9503 : Abowd, John M., Francis Kramarz et David N. Margolis, "High-Wage Workers and High-Wage Firms", janvier 1995, 73 pages

9504 : Cardia, Emanuela et Steve Ambler, "Indexation Lags and Heterodox Stabilization Programs", janvier

9605 : Garcia, René et Huntley Schaller, "Are the Effects of Monetary Policy Asymmetric?", fevrier 1995,

42 pages.

1995, 70 pages.
Parent, Daniel, "Wages and Mobility : The Impact of Employer-Provided Training", fevrier 1995, 34 pages.

9508 : Parent. Daniel, "Industry-Specific Capital and the Wage Profile : Evidence from the NLSY and the PSID", février 1995, 21 pages.

9509 : Parent, Daniel, "Matching, Human Capital, and the Covariance Structure of Eamings", février 1995. 54 pages.

9510 : Garcia, Rene, "Asymptotic Null Distribution of the Likelihood Ratio Test in Markov Switching Models", mars 1995, 50 pages.

Garcia, René, Annamaria Lusardi et Serena Ng. "Excess Sensitivity and Asymmetries in Consumption : An Empirical Investigation". mars 1995, 26 pages.

9512: Sprumont, Yves, "An Axiomatization of the Pazner-Schmeidler Rules in Large Fair Division Problems", mars 1995, 26 pages.

9513 : Ghysels, Eric, Lynda Khalaf et Cosmé Vodounou, "Simulation Based Inference in Moving Average Models", mars 1995, 10 pages.

9514 : Ng, Serena, "Looking for Evidence of Speculative Stockholding in Commodity Markets", mars 1995, 25 pages.

Ng. Serena et Huntley Schaller, "The Risky Spread, Investment, and Monetary Policy Transmission : Evidence on the Role of Asymmetric Information", mars 1995, 26 pages.

9516 : Ng, Serena, "Testing for Homogeneity in Demand Systems when the Regressors are Non-Stationary". mars 1995, 26 pages.

9517 : Ghysels, Eric. Clive W.J. Granger et Pierre L. Siklos, "Is Seasonal Adjustment a Linear or Nonlinear Data Filtering Process?", mars 1995, 34 pages. 
9518 : Ghysels, Eric. Alastair Hall et Hahn S. Lee, "On Periodic Structures and Testing for Seasonal Uni Roots", mars 1995, 45 pages.

9519: Sprumont, Yves, "On the Game-Theoretic Structure of Public-Good Economies", mars 1995, 21 pages

9520: Charles, Sandra, François Vaillancoun et Nicolas Marceau. The Impact of Decentralization on Growt and Democracy : A Note", mars 1995, 13 pages.

9521 : Sprumont, Yves, "Balanced Egalitarian Redistribution of Income", mars 1995, 17 pages.

9522 : Bronsard. Camille, Lise Salvas-Bronsard et Alain Trognon, "On the Residual Dynamics Implied by the Rational Expectations Hypothesis", mars 1995, 18 pages.

9,523 : Campbell, Bryan et Eric Ghysels, "An Empirical Analysis of the Canadian Budget Process", mars 1995 30 pages.

9524: Ghysels, Eric, Alain Guay et Alastair Hall, "Predictive Tests for Structural Change with Unknown Breakpoint", avril 1995, 29 pages.

9525 : Ghysels. Eric, "On Stable Factor Structures in the Pricing of Risk", avril 1995, 37 pages.

9526: Kollmann, Roben, "Mark Up Fuctuations in U.S. Manufacturing and Trade : Empirical Evidence Based on A Model of Optimal Storage", avril 1995, 18 pages.

9527: Laberge-Nadeau, Claire, Georges Dionne, Urs Maag, Denise Desjardins, Charles Vanasse et J.-M. Ékoe, "Medical Conditions and the Severity of Commercial Motor Vehicle (CMV) Drivers" Road Accidents", mai 1995, 26 pages.

9528 : Dionne, Georges, Manuel Aris et Montsertat Guillen, "On the Repayment of Personal Loans Under Asymmetrical Information : A Count Data Model Approach", maj 1995, 32 pages.

9529 : Ruge-Murcia, Francisco J., "Govemment Expenditure and the Dynamics of High Inflation", juin 1995. 45 pages.

9530 : Pesaran, M. Hashem et Francisco J. Ruge-Murcia, "A Discrete-Time Version of Target Zone Models with Jumps", juin 1995, 50 pages.

9531 : Dionne, Georges et N. Fombaron, "Non-Convexities and Efficiency of Equilibria in Insurance Markets with Asymmetric Information", juin 1995, 22 pages.

9532 : Bronsard, C.. P. Michel et L. Salvas-Bronsard, "Singular Demand Systems as an instrument of Scientific Discovery", juillet 1995, 17 pages.

9533: Dionne, G. et C. Fluet. "Incentives in Multi-Period Regulation and Procurement : A Graphical Analysis", juillet 1995,46 pages.

9534 : $\mathrm{Ng}$. Serena et Pierre Perron, "Estimation and Inference in Nearly Unbalanced, Nearly Cointegrated Systems", août 1995, 38 pages.

9535 : Ng. Serena et Pierre Perron. "The Exact Error in Estimating the Spectral Density at the Origin", aodt 1995, 33 pages.

9536 : Ghysels. Eric. Christian Gourieroux et Joanna Jasiak, "Market Time and Asset Price Movements : Theory and Estimation", septembre 1995, 61 pages.

9537 : Dionne, Georges, Roben Gagne et Charles Vanasse, "Inferring Technological Parameters from Incomplete Panel Data", septembre 1995, 40 pages.

9538 : Dufour, Jean-Marie et Eric Renault, "Shon-Run and Long-Run Causality in Time Series : Theory", septembre 1995, 40 pages.

9539 : Dufour, Jean-Maric, "Some Impossibility Theorems in Econometrics with Applications to Instrumental Variables, Dynamic Models and Cointegration", septembre 1995, 42 pages.

9540: Mercenier, Jean et Philippe Michel, "Temporal Aggregation in Multi-Sector Economy with Endogenous Growth", septembre 1995, 17 pages.

9541 : Loranger, Jean-Guy, "Neoliberalism and the Overwhelming Influence of Financial Markets : a Comparative Analysis between NAFTA Countries and Other G-7 Countries", septembre 1995, 34 pages.

9542 : Proulx, Pierre-Paul, "La décentralisation : facteur de développement ou d'éclatement du Québec", août 1995, 26 pages.

9543 : Arcand, Jean-Louis, Ghazi Boulila et Christian Tritten, "Intergenerational Contracts, Remittances, and Growth", octobre 1995. 57 pages.

9544: Kichian, Maral, Rene Garcia et Eric Ghysels, "On the Dynamic Specification of Intemational Asset Pricing Models", octobre 1995, 29 pages.

9545 : Arcand, Jean-Louis, "Land Ownership, Working Capital, and Agricultural Output : Egyp, 1913-1958", octobre 1995, 93 pages. 
9546 : Arcand, Jean-Louis et Marcel G. Dagenais, "The Empirics of Economic Growth in a Cross Section of Countries : Do Errors in Variables Really Not Matuer?", octobre 1995, 65 pages.

9547: Dufour, Jean-Marie et Jan F. Kiviet. "Exact Inference Methods for First-Order Autoregressive Distributed Lag Models", octobre 1995, 52 pages.

9548 : Dufour, Jean-Marie et Jan F. Kiviet, "Exact Tests for Structural Change in First-Order Dynamic Models", octobre 1995, 39 pages.

9549 : Kiviet, Jan F. et Jean-Marie Dufour, "Exact Tests in Single Equation Autoregressive Distributed Lag Models", octobre 1995, 38 pages.

9550 : Briys, Eric et Pascale Viala, "Optimal Insurance Design under Background Risk", octobre 1995, 14 pages.

Ng. Serena et Joris Pinkse, "Nonparametric Two-Step Estimation of Unknown Regression Functions when the Regressors and the Regression Error Are not Independent", octobre 1995, 22 pages.

9552 : Bai, Jushan et Pierre Perron, "Estimating and Testing Linear Models with Multiple Structural Changes", octobre 1995, 58 pages.

9553 : de Lemos Grandmont, Renato, "Mexico's Financial Liberalization and Reform. A Critical Overview", octobre 1995. 66 pages.

9554 : de Lemos Grandmont, Renato, "Multivariate Cointegration in the Presence of Structural Breaks : The Case of Money Demand in Mexico", octobre 1995, 69 pages.

Boyer, Marcel, Philippe Mahenc et Michel Moreaux, "Entry Blockading Locations", octobre 1995, 37 pages.

Boyer, Marcel et Michel Moreaux, "Capacity Commitment versus Flexibility : The Technological Choice Nexus in a Strategic Context", octobre 1995, 37 pages.

Boyer, Marcel et Jean-Jacques Laffont, "Environmental Protection, Producer Insolvency and Lender Liability", octobre 1995, 38 pages.

Montmarquene, Claude, Sophie Mahseredjian et Rachel Houle, "The Determinants of University Dropouis : a Sequential Decision Model with Selectivity Bias", decembre 1995, 17 pages.

9559 : Margolis, David N., "Cohon Effects and Returns to Seniority in France", décembre 1995, 29 pages.

9560 : Dionne, Georges et Christian Gollier, "A Model of Comparative Statics for Changes in Stochastic Retums with Dependent Risky Assets", décembre 1995, 14 pages. 